\title{
Mn-Cr chronological constraints on the thermal evolution of IIAB iron meteorite parent body
}

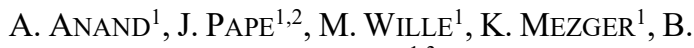 \\ HOFMANN $^{1,3}$
}

${ }^{1}$ Institut für Geologie, Universität Bern, Baltzerstrasse 1+3, 3012 Bern, Switzerland

${ }^{2}$ Institut für Planetologie, Universität Münster, WilhelmKlemm-Str. 10, 48149 Münster, Germany

${ }^{3}$ Naturhistorisches Museum Bern, Bernastrasse 15, CH-3005, Bern, Switzerland

The IIAB iron meteorites are a group of "magmatic irons", thought to sample the core of a distinct parent body that underwent large-scale chemical fractionation, most notably metal-silicate separation. Constraining the timing of core formation is essential for understanding the complete formation and cooling history of the parent body of IIAB iron meteorites. The timing and temporal extent of such early Solar System processes can be investigated using the shortlived ${ }^{53} \mathrm{Mn}-{ }^{53} \mathrm{Cr}\left(\mathrm{t}_{1 / 2} \approx 3.7 \mathrm{Ma}\right)$ chronometer.

Chromite $\left(\mathrm{FeCr}_{2} \mathrm{O}_{4}\right)$ and daubreelite $\left(\mathrm{FeCr}_{2} \mathrm{~S}_{4}\right)$ are the main carrier phases of $\mathrm{Cr}$ in IIAB iron meteorites. Both have low $\mathrm{Mn} / \mathrm{Cr}$ ratios $(\approx 0.01)$ and thus, preserve the ${ }^{53} \mathrm{Cr} /{ }^{52} \mathrm{Cr}$ of their host at the time of isotopic closure.

Model ages for chromite and daubreelite in IIAB iron meteorites can be obtained by comparing their Cr-isotope composition with the $\mathrm{Cr}$-isotope evolution of the chondritic reservoir, using Solar System initial $\varepsilon^{53} \mathrm{Cr}$, a chondritic ${ }^{55} \mathrm{Mn} /{ }^{52} \mathrm{Cr}$ and a canonical ${ }^{53} \mathrm{Mn} /{ }^{55} \mathrm{Mn}$ ratio [1]. In order to systematically resolve the ingrowth of ${ }^{53} \mathrm{Cr}$ over a time span of a few Myrs, Cr isotope abundances need to be measured with high precision by TIMS.

First results for chromite from the meteorites SikhoteAlin and Agoudal and daubreelite from NWA 11420 give an average model age of $\sim 0.8 \mathrm{Ma}$ after the formation of the Solar System. Due to the low $\mathrm{Fe} / \mathrm{Cr}$ of the samples no correction for cosmic ray exposure is necessary. These ages are in good agreement with the core formation ages in the IIAB iron meteorite parent body constrained with the short-lived ${ }^{182} \mathrm{Hf}$ ${ }^{182} \mathrm{~W}$ chronometer [2]. Additionally, the agreement between Hf-W and Mn-Cr ages within uncertainties suggests that both systems closed approximately simultaneously.

[1] Trinquier, A. et al. (2008) GCA, 72 (20), 5146-5163. [2] Kruijer, T.S. et al. (2012) GCA, 99, 287-304. 